\title{
Épocas de irrigação e parcelamento de adubação sobre a produtividade do cafeeiro, em quatro safras ${ }^{1}$
}

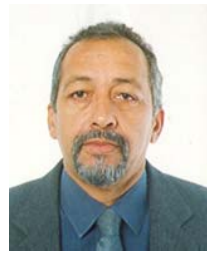

Antônio M. da Silva², Gilberto Coelho ${ }^{3}$ \& Ricardo A. da Silva ${ }^{4}$

\author{
1 Trabalho financiado pelo CNP\&D/café \\ 2 Departamento de Engenharia/UFLA. Pesquisador Bolsista CNPq. Rua Benjamin Constant 125/301. CEP 37.200-000. \\ Lavras-MG, Fone: (35) 3829-1386, E-mail: marciano@ufla.br \\ ${ }^{3}$ Doutorando em Irrigação e Drenagem/UFLA, Av. Dr. Silvio Menicucci, 521/101. 37200-000 Lavras-MG, \\ Fone: (35) 3821-9626, E-mail: coelho@ufla.br \\ ${ }^{4}$ MSc Irrigação e Drenagem. R. José Ferreira da Costa, 220, CEP 37200-000, Vila São Francisco, Lavras-MG, \\ Fone: (35) 3821-9428, E-mail: ricardoasilva@yahoo.com
}

Protocolo 110 - 25/6/2003 - Aprovado em 8/2/2005

\begin{abstract}
Resumo: Desenvolveu-se o presente trabalho, objetivando-se avaliar o efeito de diferentes épocas de irrigação e de parcelamentos de adubação na produtividade do cafeeiro em quatro safras consecutivas. Realizou-se um experimento em faixas, em que, nas parcelas foram avaliados diferentes parcelamentos de adubação: parcela 1 recebeu 12 aplicações de fertilizantes, de forma manual; parcelas 2, 3 e 4 receberam, respectivamente, 12, 24 e 36 aplicações de fertilizantes via água de irrigação. Nas faixas (subparcelas) foram avaliadas três épocas de irrigação, de 1/6 a 30/9 (subparcela A), de 15/7 a 30/9 (subparcela B), de 1/9 a 30/9 (subparcela C) e um tratamento testemunha sem irrigação (subparcela D), com 3 repetições, em blocos. Os resultados de produtividade total de café foram submetidos à análise de variância, e, quando pertinente, ao teste de comparação de médias, detectando-se efeito significativo do fator época de irrigação e safras, e, a única interação significativa foi entre safras e épocas de irrigação, indicando que a irrigação não elimina o comportamento bienal de produtividade do cafeeiro. As melhores médias de produtividade $\left(3852,2\right.$ e $\left.3527,1 \mathrm{~kg} \mathrm{ha}^{-1}\right)$ resultaram das irrigações de $1 / 6$ a 30/9 e de 15/7 a $30 / 9$, respectivamente.
\end{abstract}

Palavras-chave: manejo de irrigação, fertirrigação, ciclo bienal

\section{Irrigation timing and split application of fertilizer on productivity of the coffee plant in 4 harvests}

\begin{abstract}
The present work aimed to evaluate the effect of different periods of irrigation during and different fertilizer applications on productivity of coffee plant in 4 consecutive harvests. An experiment was accomplished in strips, in which the split fertilizer applications were tested: plot 1 received 12 applications of fertilizers in a manual way, plots 2, 3 and 4 received, respectively, 12, 24 and 36 applications of fertilizers through irrigation water. In the strips 3 irrigation periods were tested, $1 / 6$ to $30 / 9,15 / 7$ to $30 / 9,1 / 9$ to $30 / 9$ and a control treatment without irrigation, with 3 repetitions (blocks). The results of total coffee productivity expressed in $\mathrm{kg} \mathrm{ha}^{-1}$, were submitted to the variance analysis and to mean comparison test, when it was necessary. The variance analysis detected significant effect for irrigation times and in harvests. The only significant interaction was between harvest and irrigation times, showing that the irrigation does not eliminate the biennial cycle of coffee plant productivity. The irrigation from $1 / 6$ to $30 / 9$, and from $15 / 7$ to $30 / 9$ provided better mean productivity of $3,852.2$ and $3,527.1 \mathrm{~kg} \mathrm{ha}^{-1}$, respectively.
\end{abstract}

Key words: irrigation management, fertigation, biennial cycle

\section{INTRODUÇÃO}

O Brasil é o maior produtor e exportador mundial de café, além de responsável por cerca de 25\% da produção mundial e
17\% das exportações mundiais; além disso, é o segundo mercado consumidor, depois dos Estados Unidos da América. (AEC, 2001).

As áreas produtoras de café no País estão distribuídas, sobretudo, na região centro-sul, nos estados de Minas Gerais, 
Espírito Santo, São Paulo e Paraná. O Sul de Minas Gerais, em razão produzir $25 \%$ do café brasileiro, é caracterizado pela produção de cafés de excelente qualidade, devido às suas condições de clima e solo favoráveis ao desenvolvimento da cultura.

Os produtores têm adotado novas tecnologias de condução e manejo da lavoura, como o adensamento, a mecanização, inclusive da colheita, e a irrigação/fertirrigação, a fim de aumentar a produtividade e, conseqüentemente, a margem de lucro.

Hoje já são irrigados mais de 10\% dos cafezais: cerca de 35\% da área de conilon do Espírito Santo e sul da Bahia e quase $25 \%$ das culturas do oeste e leste do cerrado mineiro (FNP, 2002).

A utilização da fertirrigação oferece inúmeras vantagens em comparação com o método convencional de aplicação de fertilizantes, dentre as quais se destacam a não-compactação do solo e o fim de injúrias mecânicas nas plantas, causadas pela entrada de equipamentos pesados nas áreas de cultivo, para promover a adubação pelos métodos tradicionais; menor quantidade de equipamento exigido e menor gasto de energia; a dosagem de nutrientes pode ser mais cuidadosamente regulada, monitorada, distribuída e parcelada no perfil do solo, conforme as necessidades da cultura ao longo de seu ciclo fenológico.

Alguns questionamentos que não foram ainda devidamente esclarecidos, dizem respeito à interação entre a irrigação e o período em que os pesquisadores dizem que a cultura deve sofrer um déficit hídrico para a uniformização de florada, além do comportamento bienal da cultura quanto à sua produtividade.

Alves (1999) concluiu que a irrigação do cafeeiro por gotejamento no município de Lavras é justificável. A irrigação garantiu maior vigor à planta e eliminou os riscos advindos de secas ocasionais, elevando a produtividade do cafeeiro.

Ainda nesta região, Sorice (1999), irrigando por gotejamento com diferentes parcelamentos de adubação via água e épocas de início de irrigação, chegou à conclusão de que houve efeito significativo, tanto do parcelamento da adubação como da época de início de irrigação, proporcionando aumentos da ordem de 95 a 120\%, quando comparados com a testemunha, que produziu 24,6 sacas ha-1.

Fernandes et al. (2000), descreveram uma produtividade no ano agrícola 1997/98 igual a 45,7 sacas ha-1, em trabalho conduzido com a variedade Catuaí, com 8 anos de idade, na região de Bonfinópolis, MG e, irrigando o ano todo, com gotejadores autocompensantes da marca Katif, com vazão de $4 \mathrm{~L} \mathrm{~h}^{-1}$.

Antunes et al. (2000), usaram nos anos agrícolas 1998/99 e 1999/20000, tubo gotejador labirinto, da marca Queen Gil, com vazão média de $1 \mathrm{~L} \mathrm{~h}^{-1}$ e emissores espaçados $30 \mathrm{~cm}$ entre si. Irrigando durante o ano todo e fertirrigando a variedade Catuaí (espaçadas 2,5 x 1,0 m) com 8 anos, no município de Rio Preto, MG, região do Campo das Vertentes, obtiveram os seguintes resultados: 43,37 e 78,1 sacas ha-1 para os anos agrícolas 1998/ 99 e 1999/2000, respectivamente.

Faria et al. (2001), trabalhando na região de Lavras, MG (safra 1999/2000), com a cultivar Acaiá (plantada no espaçamento de 3,0 x 0,6 m) e irrigando o ano todo, alcançaram uma produtividade de 84,95 sacas ha-1; já Soares et al. (2001), em trabalho desenvolvido em Viçosa, na Zona da Mata do estado de Minas Gerais, com a variedade Catuaí (safra 99/00) de 8 anos de idade e plantada no espaçamento de 3,0 x 1,0 m, irrigando e fertirrigando com Hidran-plus na fórmula 19-4-19 e 9 aplicações anuais, conseguiram produtividade igual a 88,0 sacas ha ${ }^{-1}$. Em relação ao ciclo bienal do cafeeiro, Weill et al. (2000) afirmaram que as produtividades de café apresentaram acentuado ciclo bienal, para trabalhos conduzidos com a variedade Mundo Novo, no período de 1972 a 1976.

Silva et al. (2002) constataram que os tratamentos irrigados mostraram sensível acréscimo na produtividade acumulada das três primeiras safras (1998-2001), comparativamente ao não irrigado, e que, dentre os tratamentos irrigados, a produtividade apresentou-se ascendente com o aumento das lâminas de irrigação.

Embora existam vários estudos relacionados à adoção da irrigação para a cafeicultura, há também, de forma clara, muita controvérsia sobre seus efetivos efeitos, particularmente para as chamadas regiões aptas quanto ao regime hídrico; portanto, existem espaços relevantes para a condução de trabalhos com este escopo; logo, em virtude das asserções anteriores, procurou-se avaliar os efeitos de diferentes épocas da irrigação e de parcelamentos da adubação na produtividade da cultura do cafeeiro Catuaí, em quatro safras (1997/98, 1998/99, 1999/ 2000 e 2000/2001) e o comportamento da cultura com relação ao ciclo bienal de produtividade (por meio de uma análise conjunta das safras acima mencionadas).

\section{MATERIAL E MÉTODOS}

\section{Cultura e delineamento experimental}

O experimento foi instalado na Fazenda Muquem - FAEPE/ UFLA, localizada em Lavras, MG, a uma altitude de 910 m, latitude Sul $21^{\circ} 14^{\prime}$ e longitude Oeste de $45^{\circ} 00^{\prime}$, com uma cultura de café Catuaí (IAC-144) plantada no espaçamento de 0,8 m entre plantas e de 3,5 m entre linhas. Quando do início do experimento, a cultura se encontrava com 11 anos de cultivo, e, neste trabalho forma avaliados as safras 1997/1998 a 2000/2001, que se constituiu em uma das fontes de variação consideradas na análise estatística.

A área experimental foi configurada por três blocos que continham quatro parcelas, que, por sua vez, foram divididas em quatro subparcelas com oito plantas. Nas parcelas foram analisados os efeitos do número de parcelamentos de N, P e K, os quais tiveram sua distribuição casualizada, e, a aplicação, manual e via água de irrigação (fertirrigação), com as seguintes características:

- parcela 1 (P1): adubação convencional (manual), com 12 parcelamentos;

- parcela 2 (P2): adubação via água de irrigação, com 12 parcelamentos;

- parcela 3 (P3): adubação via água de irrigação, com 24 parcelamentos;

- parcela 4 (P4): adubação via água de irrigação, com 36 parcelamentos.

A aplicação de fertilizantes foi iniciada em outubro e encerrada em março. Nas subparcelas avaliou-se o efeito das 
diferentes épocas de irrigação, tratamentos esses que não tiveram sua distribuição casualizada, sendo:

- subparcela A: irrigação realizada de $1 / 6$ a 30/9;

- subparcela B: irrigação realizada de 15/7 a 30/9;

- subparcela C: irrigação realizada de 1/9 a 30/9;

- subparcela D: não irrigada e adubação manual.

Devido à não casualização dos tratamentos épocas de irrigação, este arranjo resultou num delineamento experimental com blocos casualizados com parcelas subdivididas em faixas "split block".

\section{Sistema de irrigação e manejo do experimento}

Nas três primeiras safras, a linha de irrigação constou de tubogotejadores, com vazão de $0,4 \mathrm{~L} \mathrm{~h}^{-1}$ por emissor a uma pressão de $7 \mathrm{mca}$, com emissores espaçados de 0,10 m entre si. A partir da $4^{\mathrm{a}}$ safra, a linha de irrigação passou a ser com tubos com gotejadores autocompensados inseridos na linha (in line), com espaçamento entre emissores igual a $30 \mathrm{~cm}$, vazão igual a $1,6 \mathrm{~L} \mathrm{~h}^{-1}$ para uma faixa de pressão entre 15 a 35 mca.

Obtiveram-se os dados climáticos relativos ao período de estudo, junto à estação climatológica instalada no Campus da Universidade Federal de Lavras - UFLA, distante $2 \mathrm{~km}$ do local do experimento.

Para inicio da irrigação, determinou-se a umidade do solo até a profundidade de $40 \mathrm{~cm}$, tomada como referência em virtude de concentrar maior parte das raízes do cafeeiro.

A lâmina de água aplicada durante o período que compreende os meses de junho a setembro, foi definida em função da evapotranspiração acumulada no período entre as irrigações, em número de três por semana. Fez-se o cálculo da evapotranspiração com base na evaporação do tanque Classe "A", considerando-se os coeficientes do tanque $\mathrm{K}_{\mathrm{t}}$ e da cultura $\mathrm{K}_{\mathrm{c}}$ e a precipitação ocorrida no período, conforme a Eq. 1.

$$
\mathrm{V}=\left[\left(\sum \mathrm{ECA} \times \mathrm{K}_{\mathrm{t}} \times \mathrm{K}_{\mathrm{c}}\right)-\mathrm{P}\right]
$$

em que:

$\mathrm{V}$ - volume de água a ser aplicado, $\mathrm{L}$

ECA - evaporação do tanque Classe “A” no período, mm

$\mathrm{P}$ - precipitação ocorrida no período, mm

$\mathrm{K}_{\mathrm{t}}$ - coeficiente do tanque, Doorenbos \& Kassam, (1994)

$K_{c}$ - coeficiente da cultura, Santinato et al. (1996)

A - área útil entre plantas, $\mathrm{m}^{2}$

F - fator de proporção de área molhada

O tempo de irrigação (T) foi calculado pela Eq. 2.

$$
\mathrm{T}=\frac{\mathrm{V}}{\mathrm{q}}
$$

em que:

T - tempo necessário de irrigação, em h

q - vazão do tubo gotejador, $\mathrm{L} \mathrm{h}^{-1}$

Na região de Lavras as precipitações se concentram entre os meses de outubro a março, e, embora seja o período em que ocorre a maior emissão de ramos vegetativos e o enchimento dos grãos, as irrigações se restringiram apenas às lâminas aplicadas durante a fertirrigação, e/ou, numa emergência determinada por um veranico.

A dosagem aplicada dos nutrientes foi calculada com base na análise química do solo e nas Recomendações para o Uso de Corretivos e Fertilizantes para o Estado de Minas Gerais (CFSEMG, 1989) e (CFSEMG, 1999).

Para atender às necessidades nutricionais da planta, utilizaram-se duas fontes de fertilizantes, sendo, a primeira, um adubo de fertirrigação de alta solubilidade que contém, em sua formulação, $14,5 \%$ de $\mathrm{N} ; 5,16 \%$ de $\mathrm{P}_{2} \mathrm{O}_{5} ; 32,67 \%$ de $\mathrm{K}_{2} \mathrm{O}$ e também, pequenas porcentagens de micronutrientes, e a segunda fonte usada foi um nitrato de cálcio especial, também de alta solubilidade, contendo 15,9\% de $\mathrm{N}$ e 13,1\% de CaO. As dosagens aplicadas são apresentadas na Tabela 1.

Tabela 1. Dosagens de nutrientes (g por planta) aplicadas nas quatro safras estudadas.

\begin{tabular}{cccc}
\hline Safras & $\mathrm{N}$ & $\mathrm{P}_{2} \mathrm{O}_{5}$ & $\mathrm{~K}_{2} \mathrm{O}$ \\
\hline $1997 / 98$ & 70 & 20 & 135 \\
$1998 / 99$ & 191,25 & 41,25 & 247,50 \\
$1999 / 00$ & 140,00 & 25,00 & 110,00 \\
$2000 / 01$ & 140,00 & 17,50 & 105,00 \\
\hline
\end{tabular}

Para a aplicação de fertilizantes utilizaram-se duas bombas hidráulicas injetoras. Nas safras 1997/98 e 1998/99, empregouse uma bomba com taxa de injeção da ordem de $2 \%$ da vazão do sistema de irrigação, enquanto nas safras 1999/2000 e 2000/ 2001, apenas uma bomba injetora operando com uma taxa maior de injeção, da ordem de $72 \mathrm{~L} \mathrm{~h}^{-1}$.

\section{RESULTADOS E DISCUSSÃO}

\section{Clima e lâminas aplicadas}

Observando-se a Figura 1, verifica-se, que durante os meses de junho a setembro, a evaporação do tanque classe "A” (ECA) superou substancialmente a precipitação em todos os anos agrícolas estudados. As precipitações se concentraram nos meses de outubro a março; constata-se, ainda que em todos os anos agrícolas estudados, nos meses de junho a agosto praticamente não houve precipitação e, em setembro, precipitou muito pouco. Este comportamento climático resultou num déficit hídrico médio no período de junho a setembro, de aproximadamente $300 \mathrm{~mm}$. Como há afirmações de que um déficit hídrico da ordem de $150 \mathrm{~mm}$ se torna extremamente prejudicial à cultura do café (Santinato et al., 1996) pode-se, com base nessas constatações, justificar as épocas de irrigação estudadas neste trabalho.

A Figura 2 contém os valores médios mensais para a temperatura e umidade relativa do ar, para os anos agrícolas 1997/1998 a 2000/2001. Da sua análise constata-se que, em relação a esses parâmetros, não houve condições que pudessem prejudicar a cultura (Umidade Relativa $<60 \%$ e Temperaturas $<14^{\circ} \mathrm{C}$ ).

As lâminas de irrigação e de fertirrigação aplicadas na cultura, estão apresentadas na Figura 3; verificou-se pouca variação entre a lâmina aplicada via irrigação nos anos agrícolas de 1997/1998 a 1999/2000, para uma mesma época de irrigação, 

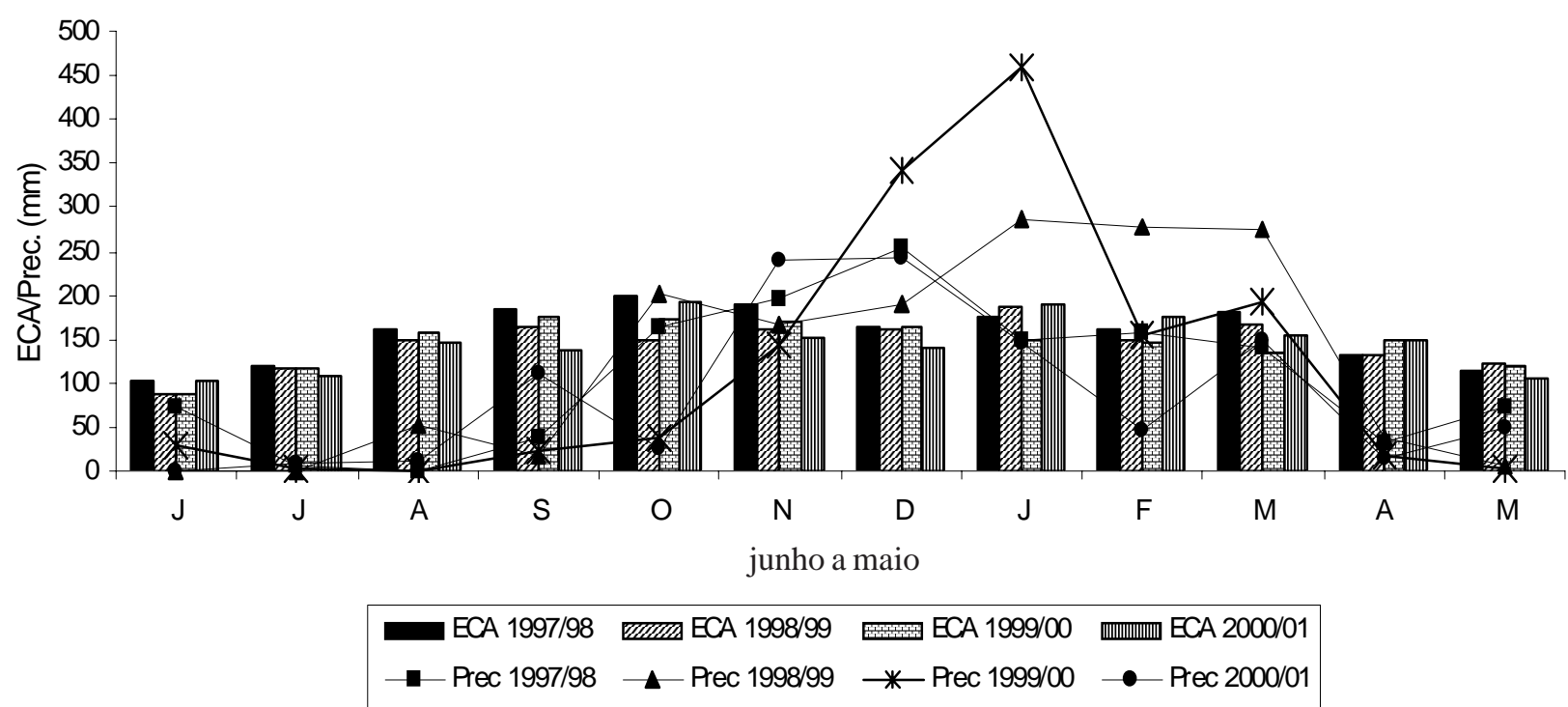

Figura 1. Totais mensais de evaporação do tanque classe “A” (ECA, mm) e de precipitação (Prec, mm), para os anos agrícolas 1997/1998 a 2000/2001

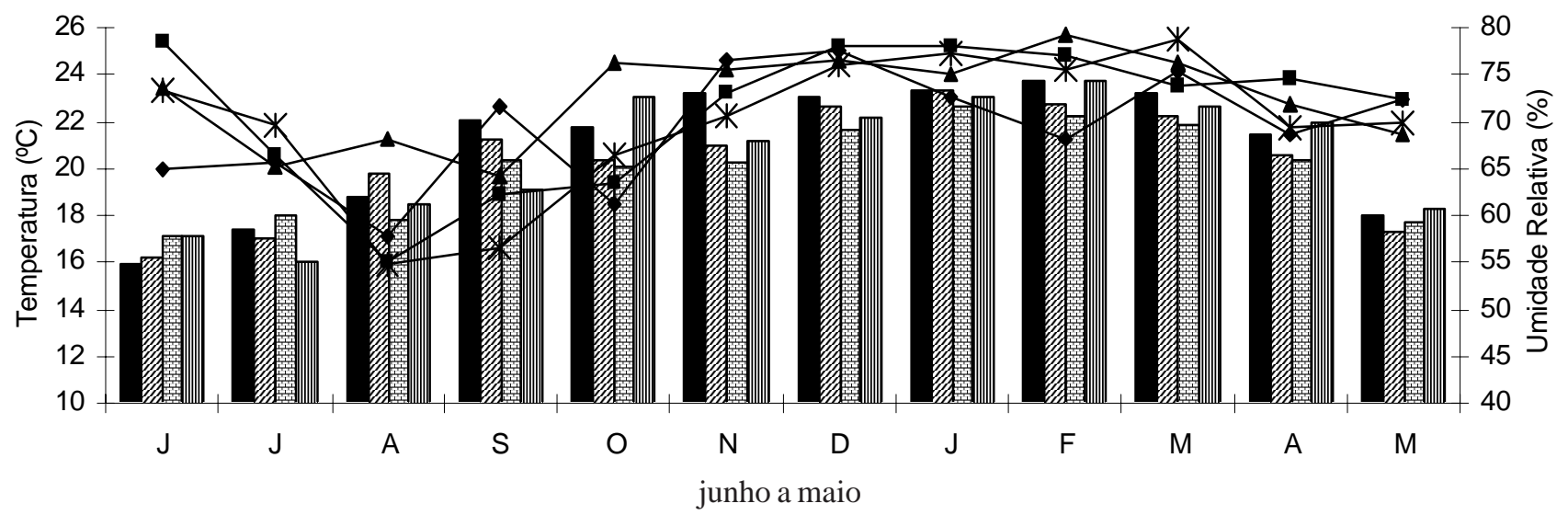

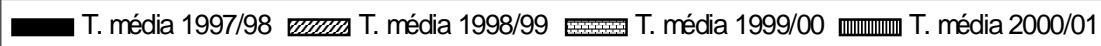

$\rightarrow-U R 1997 / 98 \rightarrow$ UR 1998/99 $\rightarrow$ *UR1999/00 $\rightarrow$ UR2000/01

Figura 2. Média mensal de temperatura e de umidade relativa, para os anos agrícolas 1997/1998 a 2000/2001

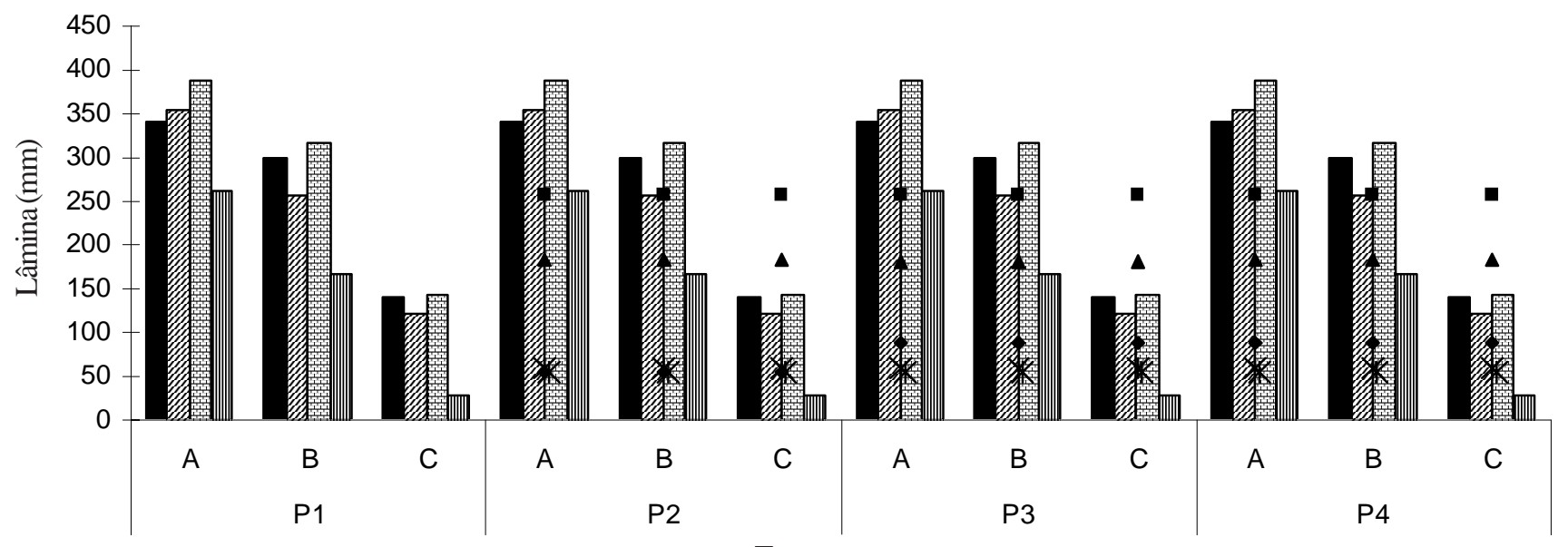

Tratamentos

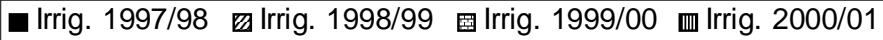

- Fert. 1997/98 A Fert. 1998/99 * Fert. 1999//00 • Fert. 2000/01

Figura 3. Lâminas aplicadas, via irrigação e fertirrigação, para os anos agrícolas de 1997/1998 a 2000/2001 
explicado face ao fato de que houve pouca variação climática entre esses anos agrícolas. No ano agrícola 2000/2001, a lâmina de irrigação recebida pelos diferentes tratamentos foi consideravelmente menor devido a precipitações ocorridas no mês de setembro do referente ano agrícola. Pôde-se observar, também, que a lâmina aplicada para se fazer a fertirrigação nos anos agrícolas 1999/2000 e 2000/2001, foi substancialmente inferior à lâmina gasta nos demais anos agrícolas, fato explicado pela troca do sistema de injeção de fertilizante que foi utilizado nas 2 primeiras safras, por outro com maior taxa de injeção de fertilizantes.

A análise de variância conjunta (temporal) para a produtividade total das safras 1997/98 a 2000/2001, está apresentada na Tabela 2, que possibilita verificar que houve diferença estatística significativa para os fatores "época de irrigação", "safras” (efeito temporal) e para a interação dos fatores safras e época de irrigação $(\alpha<1 \%)$. O fator "parcelamento de adubação" e as demais interações não apresentaram diferenças estatisticamente significativas.

Tabela 2. Análise de variância da produtividade total do cafeeiro, em relação aos fatores parcelamento de adubação, época de irrigação e safras (variação temporal), para as safras $97 / 98$ a 00/01

\begin{tabular}{|c|c|c|c|}
\hline \multicolumn{2}{|c|}{$\mathrm{FV}$} & GL & SQ \\
\hline \multicolumn{2}{|l|}{ Blocos } & 2 & $1670,28^{\text {ns }}$ \\
\hline \multicolumn{2}{|c|}{ Parcelamento de adubação } & 3 & $1603,30^{\mathrm{ns}}$ \\
\hline \multicolumn{2}{|l|}{ Resíduo (1) } & 6 & 1933,61 \\
\hline \multicolumn{2}{|c|}{ Épocas de irrigação } & 3 & $12378,65^{* *}$ \\
\hline \multicolumn{2}{|l|}{ Resíduo (2) } & 6 & 1171,43 \\
\hline \multicolumn{2}{|c|}{ Parcelamento x épocas } & 9 & $1533,31^{\mathrm{ns}}$ \\
\hline \multicolumn{2}{|l|}{ Resíduo (3) } & 18 & 3688,63 \\
\hline \multicolumn{2}{|l|}{ Safras } & 3 & $10127,61^{* *}$ \\
\hline \multicolumn{2}{|l|}{ Resíduo (4) } & 6 & 1951,57 \\
\hline \multicolumn{2}{|l|}{ Safras x parcela } & 9 & $6390,51^{\mathrm{ns}}$ \\
\hline \multicolumn{2}{|l|}{ Resíduo (5) } & 18 & 5859,67 \\
\hline \multicolumn{2}{|l|}{ Safras x épocas } & 9 & $76682,61^{* *}$ \\
\hline \multicolumn{2}{|l|}{ Resíduo (6) } & 18 & 7067,65 \\
\hline \multicolumn{2}{|c|}{ Safras x parcela x épocas } & 27 & $10717,67^{\text {ns }}$ \\
\hline \multicolumn{2}{|l|}{ Resíduo (7) } & 54 & 15246,36 \\
\hline \multicolumn{2}{|l|}{ Total } & 191 & 158013,35 \\
\hline CV 1 (\%) & CV 2 (\%) & CV $3(\%)$ & CV $4(\%)$ \\
\hline 33,03 & 25,71 & 26,34 & 33,18 \\
\hline CV 5 (\%) & & & CV 7 (\%) \\
\hline 33,19 & & & 30,91 \\
\hline
\end{tabular}

A análise de variância para o desdobramento das épocas de irrigação dentro das safras (Tabela 3), constatou diferença entre as épocas de irrigação em todas as safras estudadas. A comparação de média está presente na Tabela 5.

Vê-se, na Tabela 4 a síntese dos resultados da análise de variância com o desdobramento das safras dentro de épocas de irrigação, que demonstra a diferença significativa entre as safras para todas as épocas de irrigação. Entre outras interpretações, este resultado, permite constatar que a irrigação praticada em diferentes épocas não eliminou o comportamento bienal de produtividade do cafeeiro.
Tabela 3. Resumo da análise de variância, contendo a soma de quadrados para o desdobramento de épocas de irrigação dentro de safras

\begin{tabular}{lcc}
\hline \multicolumn{1}{c}{ Safras } & GL & SQ \\
\hline Épocas dentro da safra 97/98 & 3 & $7523,51^{* *}$ \\
Épocas dentro da safra 98/99 & 3 & $4337,10^{*}$ \\
Épocas dentro da safra 99/00 & 3 & $60144,56^{* *}$ \\
Épocas dentro da safra 00/01 & 3 & $17046,08^{* *}$ \\
Resíduo & 23 & 7895,77 \\
\hline "Significativo a 5\%; "* Significativo a 1\% & &
\end{tabular}

* Significativo a 5\%; ** Significativo a 1\%

Tabela 4. Resumo da análise de variância, contendo a soma de quadrados, para o desdobramento de safras dentro de épocas de irrigação, para a variável produtividade total

\begin{tabular}{lcc}
\hline Safras & GL & SQ \\
\hline Safras dentro de A & 3 & $34493,10^{* *}$ \\
Safras dentro de B & 3 & $7221,15^{* *}$ \\
Safras dentro de C & 3 & $35903,30^{* *}$ \\
Safras dentro de D & 3 & $9182,68^{* *}$ \\
Resíduo & 24 & 9019,21 \\
\hline
\end{tabular}

Tabela 5. Teste de comparação de médias (método de Tukey) para o desdobramento de safras dentro das épocas de irrigação, para a produtividade total

\begin{tabular}{|c|c|c|c|c|}
\hline \multirow{3}{*}{ Safras } & \multicolumn{4}{|c|}{ Subparcelas* } \\
\hline & A & B & $\mathrm{C}$ & $\mathrm{D}$ \\
\hline & \multicolumn{4}{|c|}{ Produtividade Total $\left(\mathrm{kg} \mathrm{ha}^{-1}\right)$} \\
\hline 1997/1998 & 4063,8bA & $2803,8 b B$ & $2082,0 \mathrm{bB}$ & $2411,4 \mathrm{aB}$ \\
\hline 1998/1999 & 3117,0bB & $4281,6 \mathrm{aA}$ & $4456,8 \mathrm{aA}$ & $3385,2 \mathrm{aB}$ \\
\hline $1999 / 2000$ & $6307,8 \mathrm{aA}$ & $2778,6 \mathrm{bB}$ & $951,6 \mathrm{cC}$ & $1275,6 \mathrm{bC}$ \\
\hline $2000 / 2001$ & $1920,0 \mathrm{cC}$ & $4243,8 \mathrm{aA}$ & $4910,4 a A$ & $3193,8 \mathrm{aB}$ \\
\hline Média & $3852,2 \mathrm{~A}$ & $3527,1 \mathrm{~A}$ & $3100,1 B$ & $2566,6 \mathrm{~B}$ \\
\hline CV (\%) & 41,76 & 20,87 & 52,93 & 32,33 \\
\hline
\end{tabular}

Observa-se na Tabela 5, que o tratamento irrigado de 1/6 a 30/9 apresentou maior produtividade nas safras 1997/1998 e 1999/2000; já os tratamentos irrigados de $15 / 7$ a 30/9 e de 1/9 a 30/9 proporcionaram maiores produtividades nas safras 1998/ 1999 e 2000/2001, cujos resultados confirmam que a irrigação não eliminou o ciclo bienal do comportamento da produtividade da cultura, fato constatado também por Weill et al. (2000), em ensaio com a variedade Mundo Novo, conduzido em Pindorama, SP; contudo, observando-se os valores do coeficiente de variação, pode-se dizer que, irrigando-se de $15 / 7$ a 30/9 (subparcela B) consegue-se uma redução na amplitude de variação da produtividade entre safras consecutivas, pois foi a época que apresentou o menor valor para o mesmo.

Considerando-se a média geral para cada época de irrigação, verificou-se que os tratamentos irrigados A (irrigado a partir de 1/6) e B (irrigado a partir de 15/7) não apresentaram diferença estatística, diferindo do tratamento C (irrigado a partir de 1/9) e do tratamento não-irrigado (D). Os tratamentos irrigados A e B proporcionaram produtividade de 1285,6 e $960,5 \mathrm{~kg} \mathrm{ha}^{-1}$, respectivamente, maior que a produtividade do tratamento nãoirrigado. 
Os valores médios de produtividade das quatro safras apresentados pelos tratamentos A (irrigação de $1 / 6$ a 30/9) e B (irrigação de 15/7 a 30/9) de 3852,2 e 3527,1 sacas ha-1, são extremamente relevantes, pois a produtividade do tratamento A foi superior àquelas encontradas por Santinato (2001), em dois ensaios com cafeicultura irrigada: $1^{\circ}$ ensaio: Catuaí, na região de Bonfinópolis, MG, avaliado no período de 1993 a 1999, espaçado 4,0 x 0,8 m, com aplicação de lâmina correspondente à $100 \%$ da evaporação do tanque Classe "A" (ECA) durante o ano todo, que apresentou média de produtividade de 61,6 sacas ha"-1, com a aplicação de adubo granulado diretamente ao solo; $2^{\circ}$ ensaio: Mundo Novo, na região de Planaltina, GO, avaliado no período de 1994 a 1999, espaçado 4,2 x 0,8 m, irrigado de abril a setembro, com média de produtividade de 38,0 sacas ha-1.

\section{CONCLUSÕES}

1. A prática da irrigação em Lavras, no Sul de Minas Gerais, região considerada apta ao cultivo do cafeeiro sem a utilização deste recurso, produziu efeitos significativamente positivos sobre a produtividade do cafeeiro Catuai vermelho, com 16 anos de idade.

2. As irrigações realizadas de $1 / 6$ a 30/9 e de $15 / 7$ a 30/9, propiciaram aumentos de produtividade da ordem de 37 a 50\%.

3. A irrigação não eliminou o efeito do comportamento bienal de produtividade da cultura, porém, concorreu para redução da amplitude de variação da produtividade (32,33\% de variação para 20,87\%) em safras consecutivas.

4. O parcelamento das adubações e a maneira de aplicá-las (manual ou via água de irrigação) não promoveram efeitos significativos sobre a produtividade.

\section{LITERATURA CITADA}

Alves, M.E.B. Respostas do cafeeiro (coffea arabica L.) a diferentes lâminas de irrigação e fertirrigação. Lavras: UFLA, 1999. 94p. Dissertação Mestrado

Antunes, R.C.B.; Mantovani, E.C.; Soares, A.R.; Rena, A.B.; Bonomo, R. Área de observação e pesquisa em cafeicultura irrigada na região das vertentes de Minas Gerais - resultados de 1998/2000. In: Simpósio de Pesquisa dos Cafés do Brasil, 1, 2000, Poços de Caldas. Resumos... Brasília: Embrapa Café e Minasplan, 2000. v.2, p.823-826.

AEC - Anuário estatístico do café, Rio de Janeiro: Coffee Business, 2001.161p.
CFSEMG - Comissão de Fertilidade do Solo do Estado de Minas Gerais. Recomendações para uso de corretivos e fertilizantes em Minas Gerais: 4a aproximação. Lavras, 1989. 159p.

CFSEMG - Comissão de Fertilidade do Solo do Estado de Minas Gerais. Recomendações para uso de corretivos e fertilizantes em Minas Gerais: 5a aproximação. Viçosa 1999. 360p.

Doorenbos, J.; Kassam, A.H. Efeito da água no rendimento das culturas. Campina Grande: UFPB/FAO, 1994. 306 p.

Faria, M.A. de; Vilella, W.M. da C.; Silva, M. de L.O.; Guimarães, P.T.G; Silva, E.L. da; Oliveira, L.A.M.; Silva, A.L. da. Influência das lâminas de irrigação e da fertirrigação na produtividade do cafeeiro (Coffea arabica L.) 2a colheita. In: Simpósio Brasileiro de Pesquisa em Cafeicultura Irrigada, 4, 2001, Araguari. Anais... Uberlândia: UFU/DEAGRO, 2001. p.11-14.

Fernandes, A.L.T.; Santinato, R.; Drumond, L.C.D. Lessi, R. Irrigação e utilização de granulados de solo na produção do cafeeiro. In: Simpósio de Pesquisa dos Cafés do Brasil, 1, 2000, Poços de Caldas. Resumos Expandidos... Brasília: Embrapa Café e Minasplan, 2000. v.2, p.957-959.

FNP Consultoria \& Comércio. Agrianual 2003: Anuário da agricultura brasileira. São Paulo, 2002. 546p.

Santinato, R. Avanços da tecnologia de irrigação na cultura do café. In: Simpósio Brasileiro de Pesquisa em Cafeicultura Irrigada, 3, 2000, Araguari. Palestras... Uberlândia: UFU/ DEAGRO, 2001. v.1, p.79-92.

Santinato, R.; Fernandes, A.L.T.; Fernandes, D.R. Irrigação na cultura do café. Campinas: Arbore, 1996. 146p.

Silva, A.L. da; Faria, M.A. de; Silva, M.L.O.; Costa, E.; Garcia, P.R.; Guimarães, P.T.G.; Silva, E.L. da. Produtividade das três primeiras safras do cafeeiro (Coffea arabica L.) sob diferentes lâminas de irrigação e fertirrigação. In: Simpósio Brasileiro de Pesquisa em Cafeicultura Irrigada, 5, 2002, Araguari. Anais... Uberlândia: UFU/DEAGO, 2002. P.29-32.

Soares, A.R.; Mantovani, E.C.; Rena, A.B.; Soares, A.A.; Bonomo, R. Produtividade do cafeeiro fertirrigado com fontes de nitrogênio e potássio, na região de Viçosa, MG. In: Simpósio Brasileiro de Pesquisa em Cafeicultura Irrigada, 4, 2001, Araguari. Anais... Viçosa: UFV, 2001. p.84-89. Boletim Técnico, v.1

Sorice, L.S.D. Irrigação e fertirrigação de cafeeiros em produção. Lavras: UFLA, 1999. 59p. Dissertação Mestrado

Weill, M. de A.M.; Iaffe, A.; Arruda, F.B.; Sakai, E.; Granja, N. Variabilidade da produção de café em um ensaio em Pindorama, SP. In: Simpósio de Pesquisa dos Cafés do Brasil, 1, 2000, Poços de Caldas. Resumos Expandidos... Brasília: Embrapa Café e Minasplan, 2000. v.2, p.779-781. 